IP Periodica Polytechnica Civil Engineering

\author{
60(3), pp. 345 353 2016 \\ DOI: $10.3311 /$ PPci.7983 \\ Creative Commons Attribution (1) \\ RESEARCH ARTICLE
}

\section{Some Aspects of the Operation Work of Pump Station and Water Reservoir}

\author{
Bojan Đurin
}

Received 17-02-2015, revised 05-11-2015, accepted 19-01-2016

\begin{abstract}
This paper analyzes the impact of durations and starts of water pumping into the water reservoir on the capacity of the pumping station and water reservoir volume. Two different regimes of water consumption by the population are considered in combination with three different regimes of pumping station operation. The pumping station works in accordance with the usual regimes of the water pumping into the reservoir. The pumping is continuous, from 0 to $24 \mathrm{~h}, 22$ to $6 \mathrm{~h}$ ("off-peak" period), and during the usual duration of solar radiation (from 6 to 18h). A sensitivity analysis has been conducted, in the form of observing the effect of changes in duration and start of water pumping on the pumping station capacity and reservoir volume. The purpose of this research is to determine how the resulting functional dependencies can contribute to improving the operational characteristics of the pumping station and water reservoir. Also, this research provides new insights for the scientists and practical guidelines for the water supply system managers and engineers, allowing adjustment to the changes caused by the change of pumping station and water reservoir work regimes.
\end{abstract}

\section{Keywords}

pumping station - water reservoir · duration of pumping · beginning of pumping · pumping regimes $\cdot$ water consumption regimes

\section{Bojan Đurin}

Faculty of Geotechnical Engineering, University of Zagreb, 42000 Varaždin, Hallerova Aleja 7, Croatia

e-mail: bojan.djurin@gfv.hr

\section{Introduction}

Nowadays the human population is continuously increasing in most areas and hence storage reservoirs are being and will be constructed regularly to meet the increased demand [1]. 'Municipal water reservoirs have three functions: to balance user demand (balancing storage), provide water for fire fighting (fire storage), and maintain the water supply when source interruptions occur (emergency storage)' [2]. 'Theoretically, it is most appropriate to pump water into distribution mains as per the demand pattern of the area, and in that case, there will be no need for the water reservoir, but this becomes very tedious to manage apart from being uneconomical. Thus, a service reservoir is a necessity“ [1].

Service reservoir and associated pump station, which deliver water into the reservoir when energy from the energy power system is used, are usually designed according to deterministic guidelines that specify minimal water service reservoir and optimal pump system capacity. Such guidelines have to accommodate a large range of possible conditions, meaning that systems are potentially overdesigned, but reliable. In accordance with the respective norms and particular situations, influence of fire and emergency volumes on operation volume analysis may be neglected [1,3,4]. Based on the above, only the balancing of water storage will be calculated in this paper.

In the case of using energy from the electric power network to drive the pumping station that pumps water into the water reservoir, three regimes of pumping station are usual. The first mode of water pumping (Regime I) is for a period of 24 hours during one day, while the other pumping regime is during cheaper electricity (usually in the period 22-6), or "off-peak" period (Regime II). In case solar photovoltaic PV energy is used, the pumping station works in the period in which the intensity and duration of solar radiation are such that they can produce enough electric energy for its operation (Regime III). The last depends on climate characteristics of the observed area, i.e. technological characteristics of the water supply and PV system. 


\section{Literature review}

The importance or impact of the regime of pumping on technological and economic characteristics of the entire water supply system and each of its parts (subsystem) has been described in the literature.

The example of the analyzed case study in Denmark found that 'wholesale power prices vary significantly on the hourly time scale. Flexible management of pumping rates at this time scale can result in significant cost savings in water well operation and can contribute to balancing the power market, enabling higher penetration of renewable energy sources ("smart grid"). In this approach, it is assumed that pumping rates are adjusted at the hourly time scale. In every single hourly time step, the optimal pumping rate is determined based on the present wholesale power price, the amount of water in storage and the hour of the day“ [5].

In accordance with the proposal of transforming occasional pumping regime into continuous for the case study in Palestine, [6], that recommendation is a motivation for the analysis of pumping regime in view of duration and start of pumping. The above mentioned is aimed at adjustment, i.e. transformation of the existing temporary pumping regimes to continuous regimes. [7] in the case study in Korea prove that pumping regime affects not only the cost of pumping, but also the durability and reliability of the water supply system.

In the $\mathrm{PhD}$ thesis [8], in the example of case study in United Kingdom it was established that, from hydraulic and economic point of view, more intensive pumping, i.e. pumping with increased capacity during off-peak electric energy is optimal. The same recommendation is given in [9]. The second conclusion, directly linked to the pumping regime, is that due to the increased pumping capacity it is necessary to ensure a sufficient volume of water reservoir [8].

An additional problem is temporary operation of pumps or discrete pump discharges. Thus the following applies: 'When pump speeds are considered fixed, the solutions for pump discharges are a discrete set of feasible operating points. There may also be limitations in the number of times pumps are turned "on" or "off"“ [10].

'There are two possibilities for reducing water distribution system pumping costs due to energy price; modify the pumps or modify the pumping patterns. Modifying the pumps is usually an effective way to reduce the cost due the fact that usually the pump's optimal operation conditions are not met, since the system characteristics have changed from the design process, yet this option incurs in high investment. The second option, modifying the pumping patterns, is also a feasible solution to reduce pumping costs and is easier to implement. Energy tariffs have different conditions in every country, but generally they vary according to the time of the day. When this is the situation, energy tariffs tend to be higher during peak hours, same as water demand. Based on this concept, the idea is to do most pumping during off-peak hours, in order for the pumps to use the least expensive energy' [11].

For the case of four cities in India, it has been established 'that water consumption does not change appreciably under continued water supply, if the consumer water demand is satisfied under intermittent water supply. Even short duration of water supply with enough pressure can satisfy the consumer demand better than long duration with less pressure. There is significant increase in water consumption during continuous water supply due to unmetered and unauthorized supply connections and leakages in distribution system. Water consumption patterns for slum areas, smaller and metro cities need to be studied to arrive at the general conclusion on domestic water demand under intermittent and continued water supply' [12].

The above literature review justifies the idea of analyzing the pumping station and water reservoir work regime. The fact is that 'in water supply, pumping systems represent major operational expenditure and account for the greatest use of energy' [13], which was confirmed in [14] and [15]. The set functional dependencies of the operating regime would significantly contribute to achieving the objective of economic and operational work sustainability of the water supply systems. This is supported by the fact that so far, the connection between the start and duration (regime change) of pumping and its impact on the size of the pumping station and water reservoir has not been analyzed, and thus determined and systematized.

\section{Methodology}

The capacity of the pumping station $Q_{P S}$ is defined by the equation [15]:

$$
Q_{P S}=\frac{Q_{\max , \text { daily }}}{T_{P S}}
$$

where $Q_{\text {max,daily }}\left(\mathrm{m}^{3} /\right.$ day) is maximum daily water consumption in the year, whereas $T_{P S}(\mathrm{~h})$ is the daily working time of the pumping station.

The water reservoir volume $V$ is determined by graphical or numerical procedure by integral curve methodology [15]. It is a simple procedure which is based on the fact that in the period of exchange (usually 1 day, up to 7 days) all water that flowed into the reservoir, $Q_{P S}$, flows out of it, $Q_{W S}$ :

$$
V=\max \left[\sum_{i=1}^{365}\left(Q_{P S(i), t}-Q_{W S(i), t}\right)\right], 1 \leq t \leq 24
$$

where $t$ is usually from 1 to $24 \mathrm{~h}$.

The value $Q_{W S}$ depends on water consumption regime by the users, and $Q_{P S}$ depends on the pumping station operation regime.

In each time unit within which the flow is observed in a day (typically for one hour), a certain quantity of water enters the reservoir, another quantity flows out of the reservoir, and a certain quantity remains in the system, Fig. 11 


\begin{tabular}{|c|c|c|c|c|}
\hline $\begin{array}{l}\text { Flow rate into } \\
\text { the system }\end{array}$ & $=$ & $\begin{array}{l}\text { Flow rate out } \\
\text { of the system }\end{array}$ & 1 & $\begin{array}{c}\text { Rate of } \\
\text { accumulation }\end{array}$ \\
\hline
\end{tabular}

Fig. 1. Water balance in water reservoir (modified from [16])

Water supply to a storage reservoir is generally best supplied at a fixed flow rate, which allows capital costs to be minimized and purification plants and pumps to operate at maximum efficiency. Water demand, on the other hand, is highly variable and is influenced by a large number of factors. 'The main function of a municipal storage reservoir is to balance differences between supply and demand in order to provide users with reliable water supply in the most economic way' [17].

The question arises regarding the determining of the start time and duration of pumping station operation, i.e. the regime of pumping water into the water reservoir in order to observe the impact of the above said on the capacity of the pumping station $Q_{P S}$ and reservoir volume $V$. First, the impact of different starts of pumping into the reservoir will be analyzed, for the case when the duration of water pumping is $T_{P S}=24$ hours (Regime I). In this mode, no change is expected in the required capacities of the pumping station $Q_{P S}$ and reservoir volumes $V$ for every different start of pumping. The first start of pumping is from 0 hours, and every new start is $1 \mathrm{~h}$ more than the previous.

After that, the impact of different starts of pumping water is analyzed, for this case, for water pumping regime in the "offpeak" period (Regime II), and the pumping regime when PV energy is used (Regime III). Naturally, it is understood that in Regime II and III water pumping, i.e. pumping station operation won't last 24 hours as in Regime I, but will be shorter. All three regimes of water flow into the reservoir are analyzed with respect to the two water consumption regimes by the users.

Also, longer period of water pumping $T_{P S}$ into the water reservoir requires smaller reservoir volume $V$.

After determining the required pumping station $Q_{P S}$ and reservoir volume $V$ for the above regimes of water consumption and pumping, we determine the existence of functional dependence between the obtained capacities of the pumping station $Q_{P S}$ and different duration of water pumping into the reservoir $T_{P S}$. The existence of functional dependence between the reservoir volume $V$ and different duration of water pumping $T_{P S}$ is also determined. We also want to determine the connection between the pumping station capacity $Q_{P S}$ and reservoir volume $V$ (and vice versa) for Regimes II and III.

\section{Results and Discussion}

\subsection{Case study}

Two common regimes of water consumption, Regime W1 and Regime W2, are observed in a hypothetical example of settlement located in the coastal part of Croatia, Fig. 2 and 3 . The number of inhabitants in the settlement is 8970 . Specific water consumption for $q_{\text {spec }}$ is $1901 /$ day per capita. Yearly water consumption $Q_{\text {yearly }}$ is $621960 \mathrm{~m}^{3} /$ year, while the regime of daily and hourly consumption is characterized by maximum coefficients of daily and hourly unevenness of consumption, $K_{D}$ and $K_{H}$. For Regime W1, $K_{H}=1.68$, and for W2, $K_{H}=2.52$. Coefficients of daily unevenness are equal for both water consumption regimes and are $K_{D}=1.43$.

Average daily water consumption is $Q_{\text {aver,daily }}=1704 \mathrm{~m}^{3} /$ day. Maximum daily consumption is $Q_{\text {max } \text {, daily }}=2440 \mathrm{~m}^{3} /$ day for Regime W1 and Regime W2. Average hourly water consumption $Q_{\text {aver,hourly }}$ is $102 \mathrm{~m}^{3} / \mathrm{h}$ for Regime W1 and Regime W2.

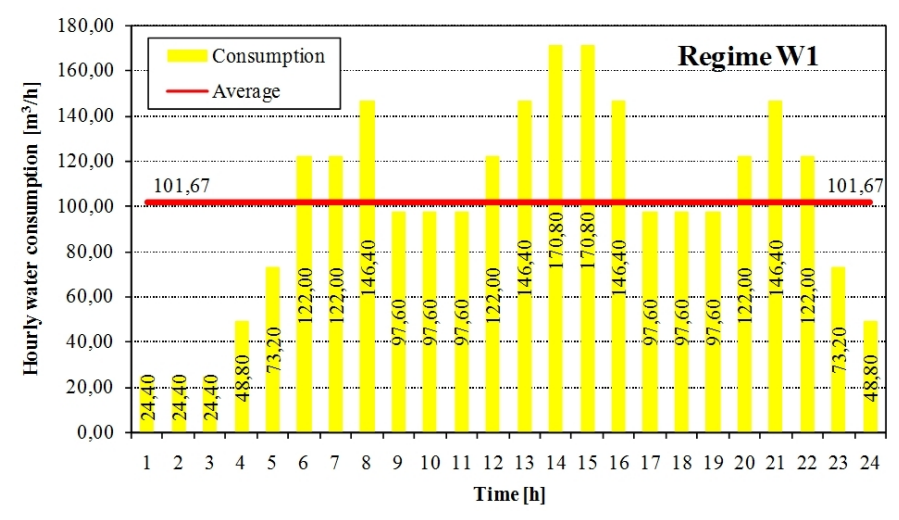

Fig. 2. Water consumption profile for Regime W1

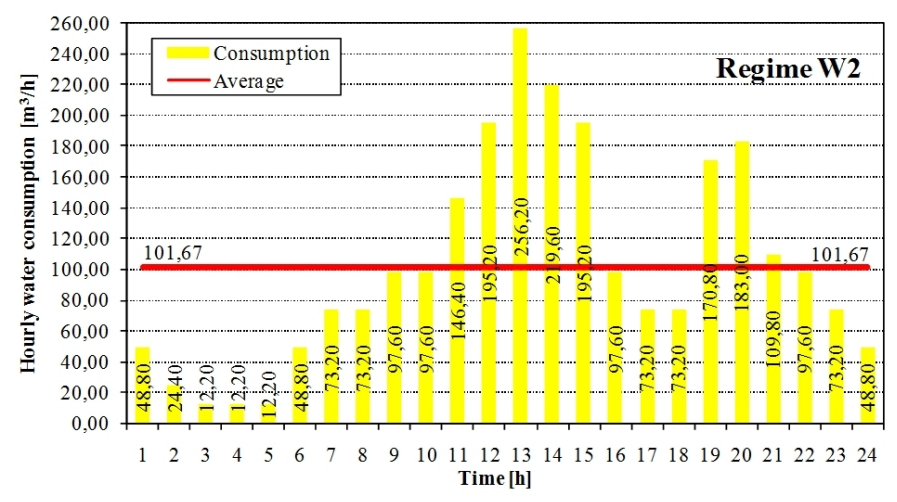

Fig. 3. Water consumption profile for Regime W2

In addition to water consumption regimes $\mathrm{W} 1$ and $\mathrm{W} 2$, three previously mentioned regimes of pumping water into the reservoir have been defined:

- Regime I (from 0 to $24 \mathrm{~h}$ ) by using classical electric energy;

- Regime II ("off-peak" hours from 22 do 6) by using classical electric energy;

- Regime III (period of solar radiation from 6 to 18) by using PV energy.

It is adopted that in every hour the pumping station pumps a constant amount of water into the reservoir.

\subsection{Analysis of Regime I}

First, we analyze the effect of different pumping starts for Regime I within 24 hours, starting at 1 o'clock, where each new start is 1 hour later than the previous one. Every new step of pumping duration is two hours. Every hour $Q_{P S}=102 \mathrm{~m}^{3} / \mathrm{h}$ is 
pumped into the reservoir for consumption regime $\mathrm{W} 1$ and $\mathrm{W} 2$, Fig. 4 The value $Q_{P S}$ is obtained by Eq. (1). By Eq. (2), the following reservoir volumes are obtained, Fig. 5 For consumption regime $\mathrm{W} 1$ reservoir volume $V$ is $394 \mathrm{~m}^{3}$, while for regime $\mathrm{W} 2$ the reservoir volume $V$ is $602 \mathrm{~m}^{3}$. It is evident that in the case of pumping water in the duration of $T_{P S}=24$ hours (Regime I) the different start of pumping has no effect on the pumping station capacity $Q_{P S}$ and reservoir volume $V$ in both regimes of consumption by users, W1 and W2.

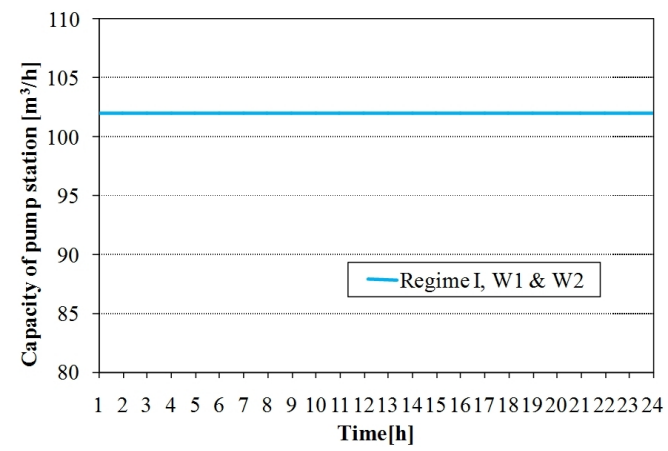

Fig. 4. Capacity of the pump station for Regime I and Regime W1 \& W2

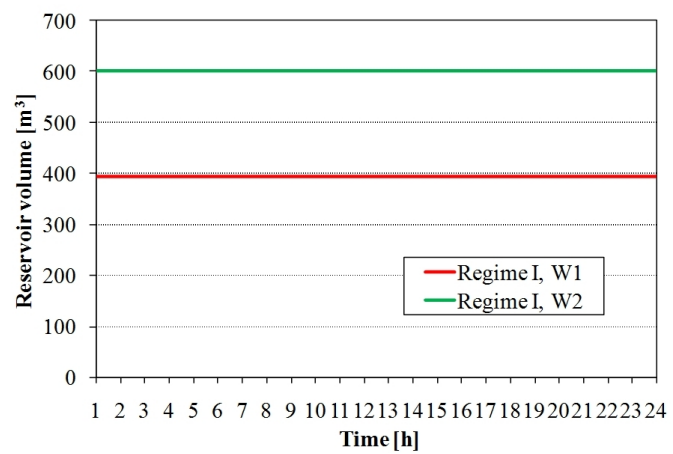

Fig. 5. Volume of the water reservoir for Regime I and Regime W1 \& W2

The analysis of Fig. 4 and 5 shows that there is a constant relationship between the pumping station capacity $Q_{P S}$ and duration of pumping $T_{P S}$ which is $24 \mathrm{~h}$ :

$$
Q_{P S}=\text { const } \text {. }
$$

For the reservoir volume $V$ also applies:

$$
V=\text { const }
$$

It is also useful to have an insight into the cumulated hourly inflow and outflow to see how the reservoir balances the daily variation in demand for the two analyzed scenarios, W1 and W2, for the Regime I., Fig. 6 and Fig. 7

In Figures 6 and 7 it is evident that daily peaking of the inflow and outflow is achieved, since at the end of the time series of pumping (at $24 \mathrm{~h}$ ) the curves end in the same point which is equal to $Q_{\text {max,daily }}=2440 \mathrm{~m}^{3} / \mathrm{day}$ ). It is obvious that the same conclusions must be obtained for Regime II and III, therefore, they are not specifically stated.

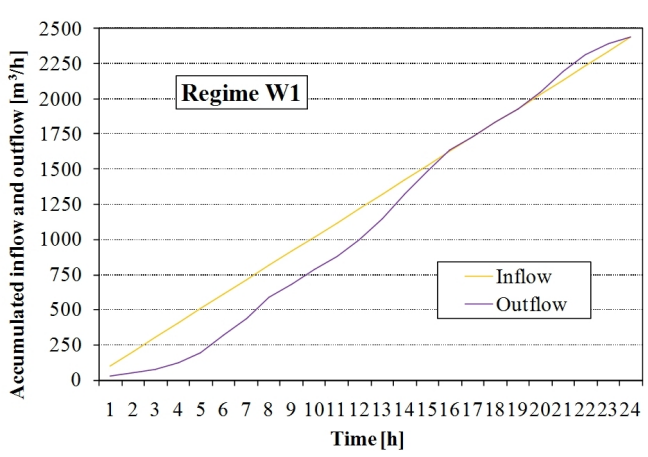

Fig. 6. Cumulated daily inflow and outflow for the Regime W1

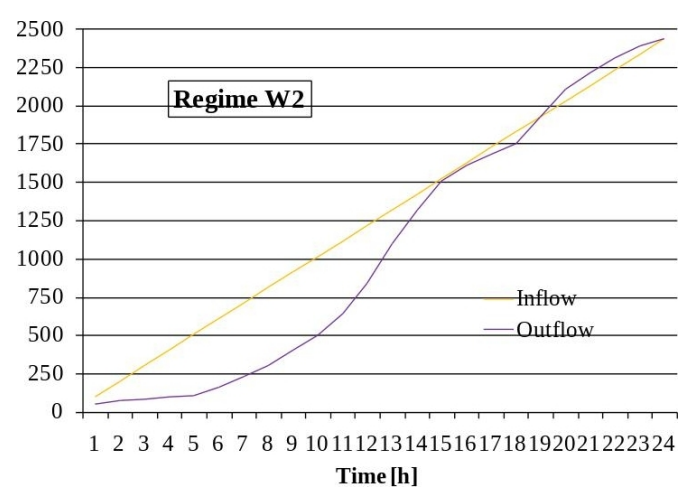

Fig. 7. Cumulated daily inflow and outflow for the Regime W2

\subsection{Analysis of Regime II}

In case the pumping time $T_{S}$ is less than 24 hours in one day, different pumping starts affect the reservoir volume $V$. Changes in the pumping station capacity $Q_{P S}$ and reservoir volume $V$ are analyzed in view of water pumping regime in "off-peak" period, from 22 to 6 (Regime II) for both water consumption regimes by the population, $\mathrm{W} 1$ and $\mathrm{W} 2$.

First, the change in pumping station capacity $Q_{P S}$ is analyzed, followed by the analysis of changes in reservoir volume $V$ for Regime II and Regime of water consumption W1. The pumping of water into the reservoir starts from $22 \mathrm{~h}$ and ends at $6 \mathrm{~h}$. The minimum duration of pumping is $T_{P S}=2$ hours, and maximum is $T_{P S}=8$ hours. Each new pumping time step is 2 hours. The required pumping station capacities $Q_{P S}$, obtained by Eq. (1) are presented in Fig. 8 Water reservoir volumes $V$, obtained by Eq. (2) are presented in Fig. 9

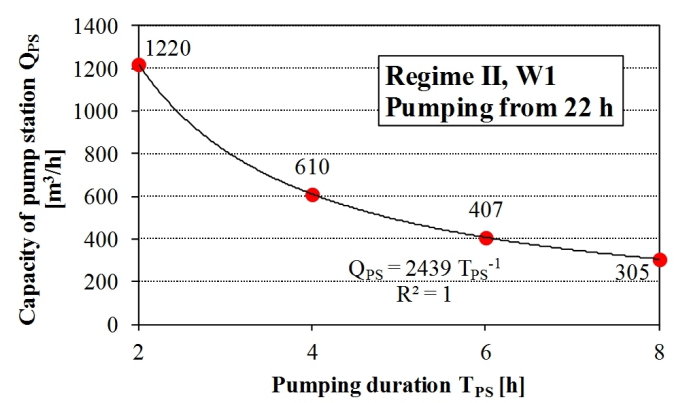

Fig. 8. Capacity of the pump station for Regime I and Regime W1 for water pumping from $22 \mathrm{~h}$

The resultant is an exponential dependence between the capacity of the pumping station $Q_{P S}$ and pumping time $T_{P S}$. The 


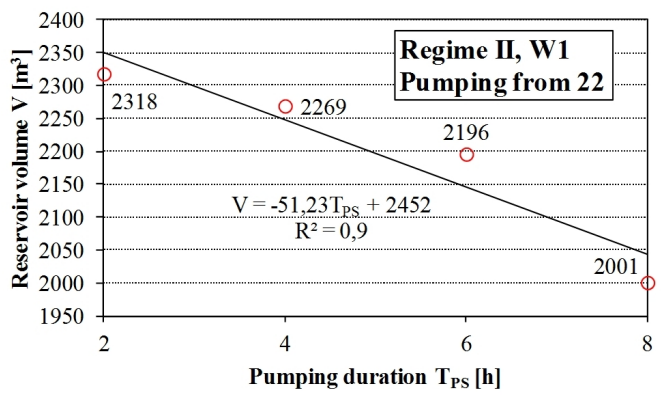

Fig. 9. Volume of the water reservoir for the Regime II and Regime W1 for water pumping from $22 \mathrm{~h}$

obtained dependence is complete, as is evident from the values of the determination coefficient $R^{2}$ which is 1 . With longer pumping time $T_{P S}$, the pumping station capacity $Q_{P S}$ becomes smaller and vice versa.

A linear dependence is obtained between the reservoir volume $V$ and duration of pumping $T_{P S}$. The determination coefficient $R^{2}$ is also very high and equals 0.9 , which indicates a significant correlation. There is a noticeable tendency of reducing the reservoir volume $V$ with increasing duration of pumping into the reservoir, $T_{P S}$, and vice versa.

For the purpose of further verification of the conclusions drawn, a sensitivity analysis has been performed, with respect to the start and duration of pumping, with new pumping start at $20 \mathrm{~h}$, and ending at $8 \mathrm{~h}$, with minimum pumping time again $T_{P S}=2$ hours, while this time the maximum pumping time is $T_{P S}=12$ hours, Fig. 10 and 11 . Each new step of pumping in this case is $2 \mathrm{~h}$.

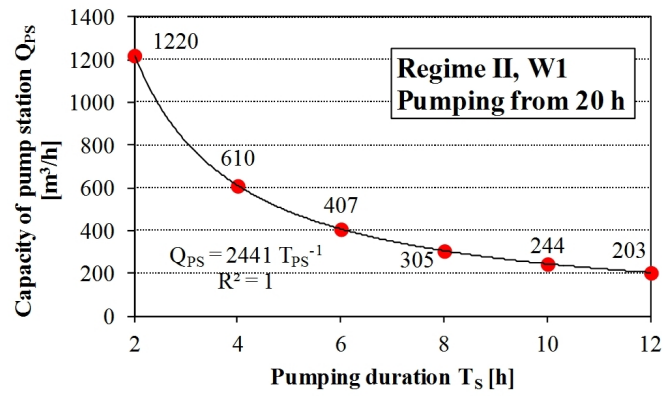

Fig. 10. Capacity of the pump station for Regime II and Regime W1 for water pumping from $20 \mathrm{~h}$

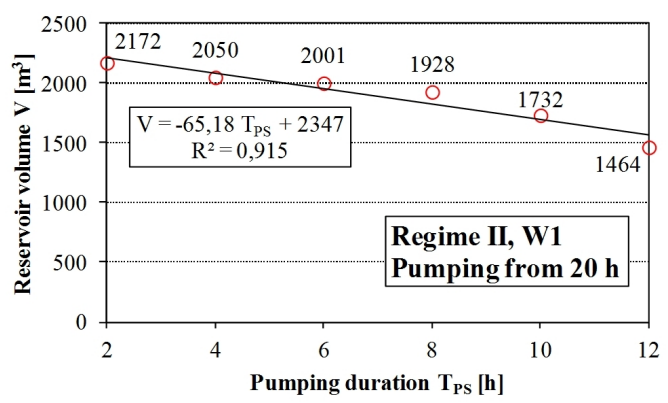

Fig. 11. Volume of the water reservoir for Regime II and Regime W1 for water pumping from $20 \mathrm{~h}$

Exponential dependence of the pumping station capacity $Q_{P S}$ on pumping time $T_{P S}$ was also obtained in this case, with determination coefficient $R^{2}$ once again equals 1 . Again, the linear relationship between the reservoir volume $V$ and pumping time $T_{P S}$ is obtained, with a very high determination coefficient $R^{2}=0.915$. Linear relationship between $V$ and $T_{P S}$ is hereby confirmed.

Fig. 12 shows the correlation between the pumping station capacity $Q_{P S}$ and reservoir volume $V$ for pumping from $22 \mathrm{~h}$ and at $20 \mathrm{~h}$, Fig. 13 Exponential relationship proved to be the most appropriate for this case. This resulted in functional dependence with a significant connection, as is evident from the size of the determination coefficient, $R^{2}=0.764$ for pumping from $22 \mathrm{~h}$, or $R^{2}=0.764$ for pumping from $20 \mathrm{~h}$. It can be seen here that with the increase of the pumping station capacity $Q_{P S}$, the reservoir volume is higher and vice versa.

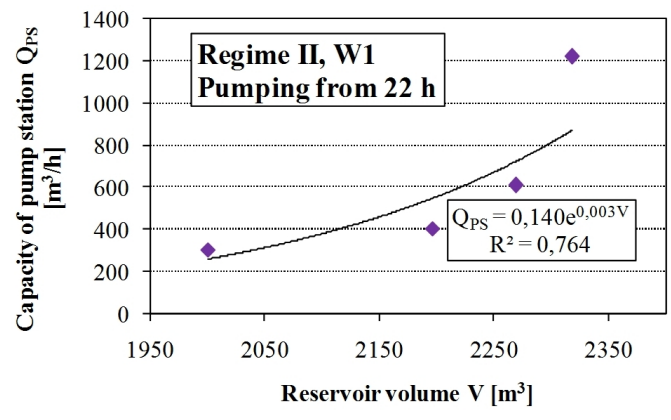

Fig. 12. Capacity of the pump station and volume of the water reservoir for Regime II and Regime W1 for water pumping from $22 \mathrm{~h}$

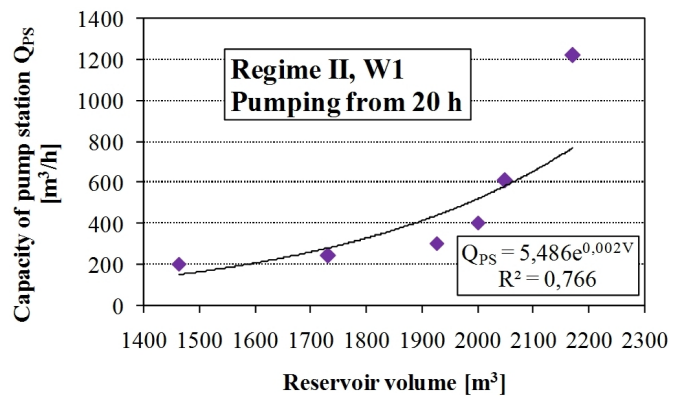

Fig. 13. Capacity of the pump station and volume of the water reservoir for Regime II and Regime W1 for water pumping from $20 \mathrm{~h}$

Analogue procedure was carried out for the second regime of water consumption, W2. The results are shown in Fig. 14 and 15. It should be noted that in this case the pumping regime, i.e. inflow of water into the reservoir is the same as in pumping regime W1 (Fig. 8 and 10), therefore it will not be presented.

Again, a significant linear dependence can be seen ( $R^{2}=0.968$ for pumping from $22 \mathrm{~h}$, and $R^{2}=0.952$ for pumping from $20 \mathrm{~h}$ ) between reservoir volume $V$ and pumping duration $T_{P S}$, as can be seen for water consumption regime $\mathrm{W} 1$.

Fig. 16 shows exponential relationship between the pumping station capacity $Q_{P S}$ and reservoir volume $V$ for Regime W2 for pumping start from $22 \mathrm{~h}$, or $20 \mathrm{~h}$, Fig. 17

Here it can also be observed that significant correlation between the pumping station capacity $Q_{P S}$ and reservoir volume 


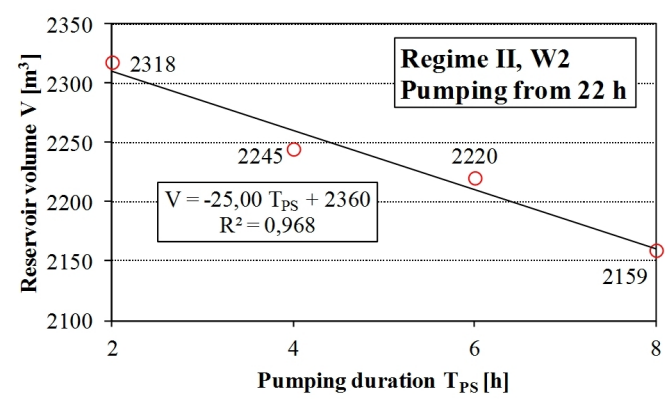

Fig. 14. Volume of the water reservoir for Regime II and Regime W2 for water pumping from $22 \mathrm{~h}$

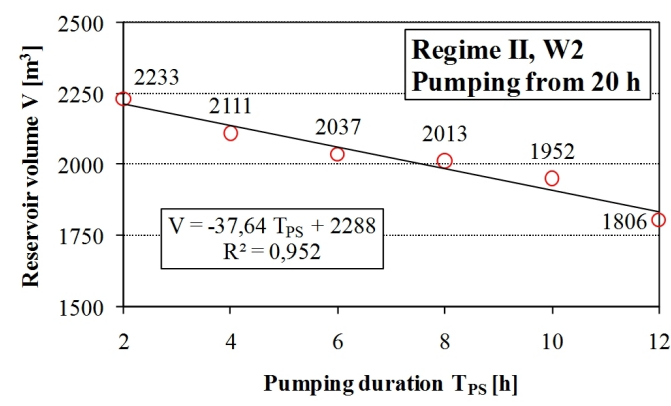

Fig. 15. Volume of the water reservoir for Regime II and Regime W2 for water pumping from $20 \mathrm{~h}$

$V$ can be seen for both pumping starts. $R^{2}=0.963$ for pumping start from $22 \mathrm{~h}$, and $R^{2}=0.908$ for pumping start from $20 \mathrm{~h}$. It can rightfully be concluded that there is an exponential dependence between the pumping station capacity $Q_{P S}$ and reservoir volume $V$.

Based on the analysis of Regime II, the resulting functional dependences can be written in a general form. The following relation applies for the pumping station capacity $Q_{P S}$ and duration of pumping $T_{P S}$ :

$$
Q_{P S}=Q_{m a x, d a i l y} T_{P S}^{-1}
$$

For the reservoir volume and pumping time $T_{P S}$, the following relation applies:

$$
V=a T_{P S}+Q_{\max , d a i l y}
$$

And finally, the following relation applies for the pumping

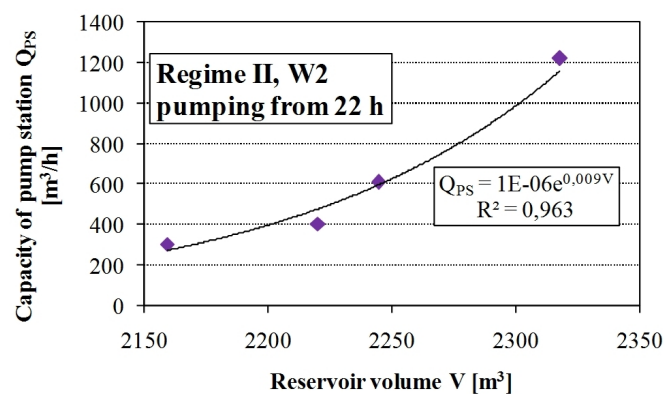

Fig. 16. Capacity of the pump station and volume of the water reservoir for Regime II and Regime W2 for water pumping from $22 \mathrm{~h}$

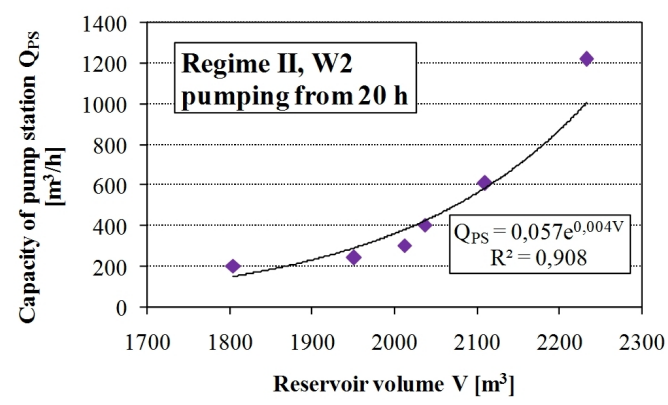

Fig. 17. Capacity of the pump station and volume of the water reservoir for Regime II and Regime W2 for water pumping from $20 \mathrm{~h}$

station capacity $Q_{P S}$ and reservoir volume $V$ :

$$
Q_{P S}=b e^{c V}
$$

where $a, b$ and $c$ are coefficients which depend on the water consumption regime and they are obtained by the method of least squares.

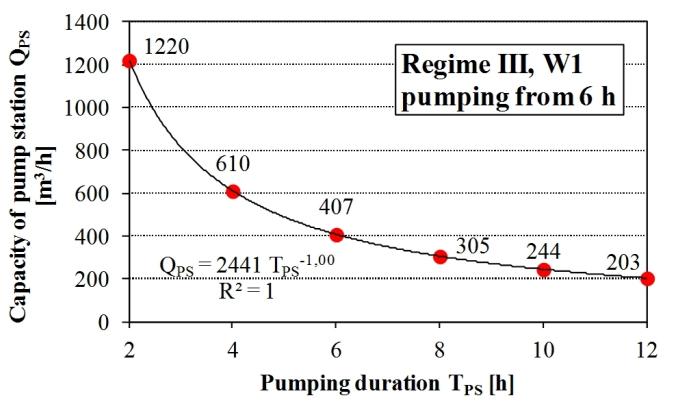

Fig. 18. Capacity of the pump station for Regime III and Regime W1 for water pumping from $6 \mathrm{~h}$

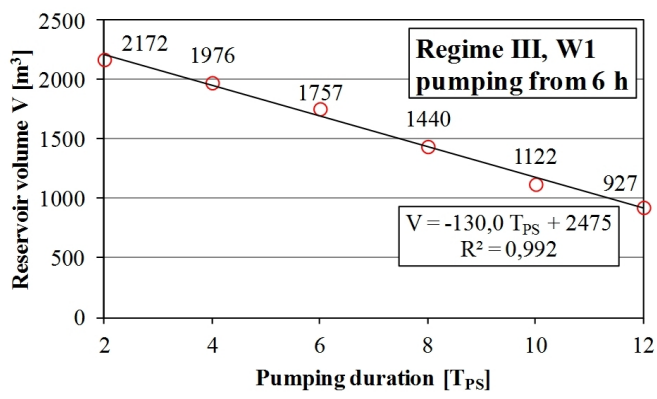

Fig. 19. Volume of the water reservoir for Regime III and Regime W1 for water pumping from $6 \mathrm{~h}$

\subsection{Analysis of Regime III}

In this case it is assumed that the intensity and duration of solar radiation are sufficient to ensure continuous work of the pumping station i.e. pumping of water into the reservoir in the required periods of inflow. The results are shown in Fig. 18 27 The pumping starts at $6 \mathrm{~h}$ and lasts until $18 \mathrm{~h}$ and from $8 \mathrm{~h}$ until $16 \mathrm{~h}$, which is characteristic for the usual duration of solar radiation. Hereinafter, the same procedure was performed as in Regime II, so it will not be described to avoid unnecessary repetition. 


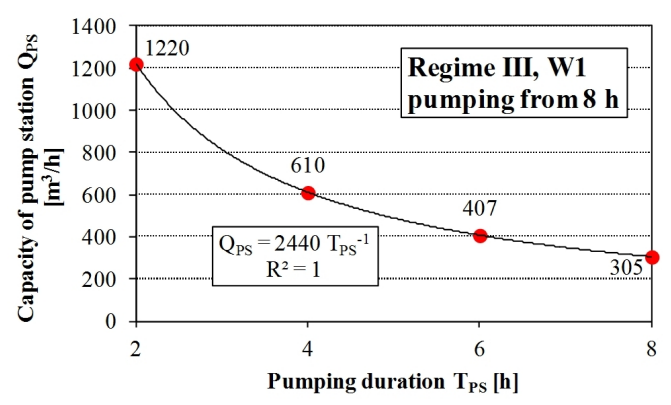

Fig. 20. Capacity of the pump station for Regime III and Regime W1 for water pumping from $8 \mathrm{~h}$

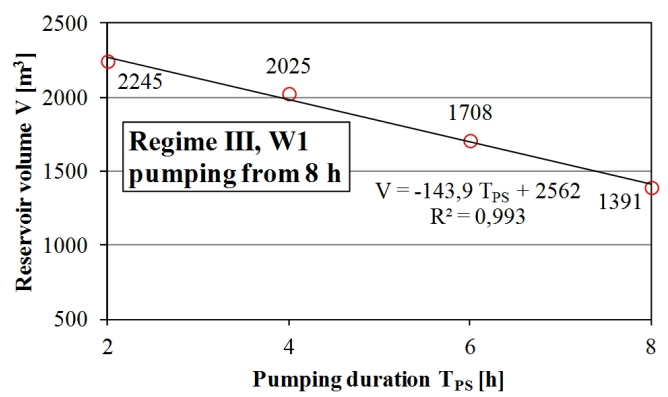

Fig. 21. Volume of the water reservoir for Regime III and Regime W1 for water pumping from $8 \mathrm{~h}$

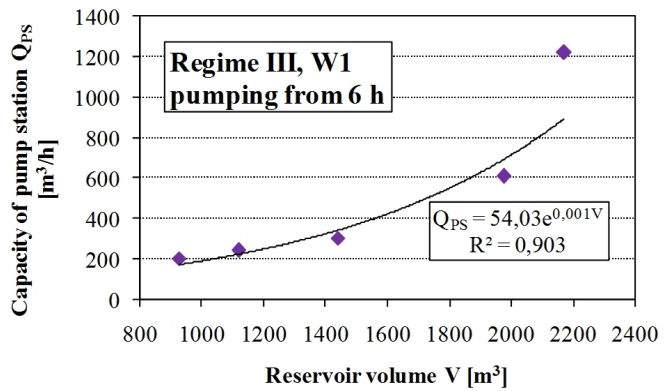

Fig. 22. Capacity of the pump station and volume of the water reservoir for Regime III and Regime W1 for water pumping from $6 \mathrm{~h}$

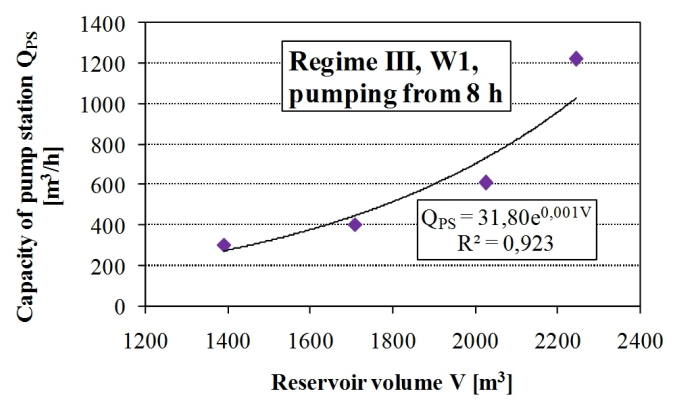

Fig. 23. Capacity of the pump station and volume of the water reservoir for Regime III and Regime W1 for water pumping from $8 \mathrm{~h}$

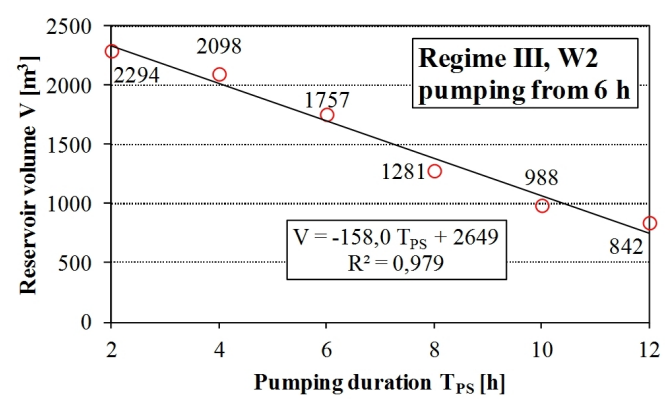

Fig. 24. Volume of the water reservoir for Regime III and Regime W2 for water pumping from $6 \mathrm{~h}$

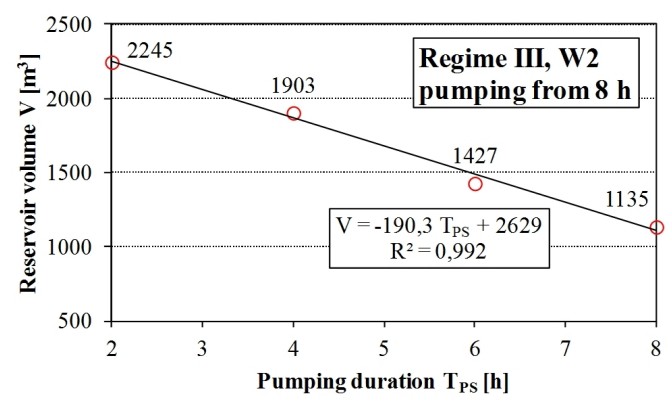

Fig. 25. Volume of the water reservoir for Regime III and Regime W2 for water pumping from $8 \mathrm{~h}$

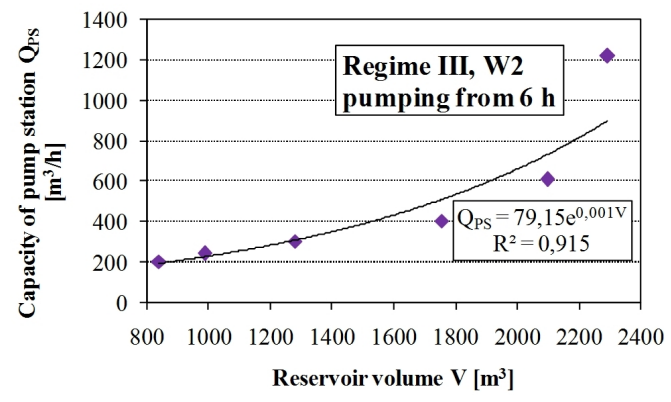

Fig. 26. Capacity of the pump station and volume of the water reservoir for Regime III and Regime W2 for water pumping from $6 \mathrm{~h}$

Analysis for water consumption regime W2 was carried out, (Fig. 24-27) analogous to the previous analysis of water consumption regime $\mathrm{W} 1$.

The analysis of the obtained functional dependences for Regime III also confirms the functional relations obtained by the same analysis for Regime II, presented by Eqs. (5) - (7).

\section{Conclusions}

This research has established certain functional connections between the pumping station capacity $Q_{P S}$, reservoir volume $V$, and duration of pumping $T_{P S}$ with respect to certain starts of pumping in view of characteristic pumping regimes, which are: constant pumping in the duration of 24 hours (Regime I), "off peak" period from 22 to $6 \mathrm{~h}$ (Regime II) and pumping in the case solar photovoltaic (PV) energy is used (Regime III). In order to facilitate comparisons and drawing conclusions, for each of the three pumping regimes (Regime I, Regime II and Regime III), two water consumption regimes are defined, Regime W1 and Regime W2.

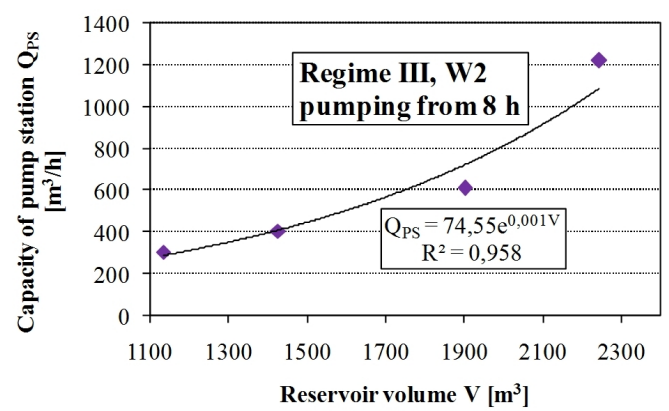

Fig. 27. Capacity of the pump station and volume of the water reservoir for Regime III and Regime W2 for water pumping from $8 \mathrm{~h}$ 
Certain functional dependences have been determined after the performed analysis. Specifically, it is about power dependence between the pumping station capacity $Q_{P S}$ and duration of pumping $T_{P S}$. After that, linear relationship between the reservoir volume $V$ and duration of pumping $T_{P S}$ was determined. Finally, exponential dependence between the pumping station capacity $Q_{P S}$ and reservoir volume $V$ was determined. These dependencies are determined for water pumping Regimes II and III into the reservoir, as well as for both regimes of water consumption, W1 and W2. For Regime I these dependencies are constant, because there are no changes in the capacity of the pumping station $Q_{P S}$ and volume of water reservoirs $V$, as water pumping is constant throughout the day ( $0-24$ hours), as opposed to pumping water in Regime II and III.

The purpose of power dependence between the capacity of the pumping station $Q_{P S}$ and duration of pumping $T_{P S}$ is to determine the increase or decrease of the pumping station capacity $Q_{P S}$ if the need arises to change the existing pumping regime. This is especially important if, for example, instead of the usual "off-peak" period, pumping is performed during solar radiation, i.e. when using PV energy or vice versa.

Linear dependence between the reservoir volume $V$ and duration of pumping $T_{P S}$ shows that it is sufficient to know, or calculate, the reservoir volume $V$ at the start and end of pumping in view of specific duration of pumping $T_{P S}$. The other necessary reservoir volumes $V$ between the start and end of pumping are determined by the resulting linear dependence between $V$ and $T_{P S}$. The above has an application in cases of change of pumping station regime for the case of reducing or increasing the duration of pumping $T_{P S}$. It is determined here whether the existing reservoir volume $V$ can meet such a change in the duration of pumping $T_{P S}$. In other words, we want to give an answer to the question whether the reservoir volume $V$ will be sufficient to accept some other amount of water that comes into the reservoir. As in the case of dependency between the capacity of the pumping station $Q_{P S}$ and duration of pumping $T_{P S}$, this also has significant application if, for example, instead of the usual "offpeak" period, pumping is performed during solar radiation, i.e. when using PV energy or vice versa.

The purpose of exponential dependence between the capacity of the pumping station $Q_{P S}$ and reservoir volume $V$ is to check the required capacity of the pumping station $Q_{P S}$ or reservoir volume $V$ if the need arises for increasing or decreasing the reservoir $V$, as well as in the case of the need to reduce or increase the capacity of the pumping station $Q_{P S}$. The increase or decrease of the pumping station capacity $Q_{P S}$ or reservoir volume $V$ is determined by the obtained power relationship. As in the relationship between $Q_{P S}$ and $T_{P S}$, and also $V$ and $T_{P S}$, the exponential dependence between $Q_{P S}$ and $V$ is important if, for example, instead of the usual "off-peak" period, pumping is performed during solar radiation, i.e. when using PV energy or vice versa.

When pumping water into the reservoir from 0-24 hours
(Regime I), the pumping station capacity and reservoir volumes are minimum, with respect to Regimes II and III. The pumping station capacity and reservoir volume in Regimes II and III are approximately the same. Therefore, the choice between the regime of pumping water into the reservoir, Regime II and III, mainly depends on the selection of energy sources to operate pumping stations (conventional energy from the power network or PV energy). SWOT analysis, cost-benefit analysis, as well as the application of multi-criteria methods should be relied upon. The multi-criteria methods are nowadays particularly important, because in addition to economic objectives, environmental and social objectives should be met. In other words, the selected solution must be sustainable with respect to the above three objectives (criteria).

The resulting conclusions and functional dependencies are primarily intended for analysis and change in the existing operating regime of the already built water supply systems. The emphasis is on the work of pumping stations and water reservoirs. Normally, the displayed functional dependences can also be used in the planned water supply systems. It is useful to examine possible changes in the capacity of the pumping station and water reservoir volume that can happen during a future time.

No matter what kind of analysis is performed on the hypothetical example of the settlement located in Croatia, the presented research is applicable to any location in the world. In doing so, actual local climate, social and technological characteristics of the observed area, or water supply system, must be taken into account.

\section{References}

1 Bhargava D S, Gupta P K, Variation effects on the economical design of service reservoirs, Indian Journal of Engineering \& Material Sciences, 11(2), (2004), 107-112.

2 van Zyl J E, le Gat Y, Piller O, Walski T M, Impact of Water Demand Parameters on the Reliability of Municipal Storage Tanks, Journal of Water Resources Planning and Management, 138(5), (2012), 553-561, DOI 10.1061/(ASCE)WR.1943-5452.0000200

3 Đurin B, Margeta J, Analysis of the Possible Use of Solar Photovoltaic Energy in Urban Water Supply Systems, Water, 6(6), (2014), 1546-1561, DOI 10.3390/w6061546

4 Malus D, Vouk D, Grljak A, Primjena Pravilnika o Hidrantskoj Mreži za Gašenje Požara u Ruralnim Područjima, Graðevinar, 63(11), (2011), 953960.

5 Bauer-Gottwein P, Schneider R, Davidsen C, Optimizing Wellfield Operation in a Variable Power Price Regime, Groundwater, 54(1), (2016), 92103, DOI 10.1111/gwat.12341

6 Abu-Madi M, Trifunović N, Impacts of supply duration on the design and performance of intermittent water distribution systems in the West Bank, Water International, 38(3), (2013), 263-282, DOI 10.1080/02508060.2013.794404

7 Kim M, Choi T, Kim M, Han S, Koo J, Optimal operation efficiency and control of water pumps in multiple water reservoir system: case study in Korea, Water Science \& Technology: Water Supply, 15(1), (2015), 59-65, DOI 10.2166/ws.2014.079

8 Saadeldin Saleh AbdelMeguid H, Pressure, Leakage and Energy Management in Water Distribution Systems, PhD thesis, De Montfort University; Leicester, UK, 2011. 
9 Giustolisi O, Laucelli D, Berardi L, Operational Optimization: Water Losses versus Energy Costs, Journal of Hydraulic Engineering, 139(4), (2013), 410-423, DOI 10.1061/(ASCE)HY.1943-7900.0000681

10 Nitivattananon V, Sadowski E C, Quimpo R G, Optimization of Water Supply System Operation, Journal of Water Resources Planning and Management, 122(5), (1996), 374-384, DOI 10.1061/(ASCE)07339496(1996)122:5(374)

11 Bohórqueza J, Saldarriaga J, Vallejoa D, Pumping Pattern Optimization in Order to Reduce WDS Operation Costs, Procedia Engineering, 119, (2015), 1069-1077, DOI 10.1016/j.proeng.2015.08.936

12 Andey S P, Kelkar P S, Influence of Intermittent and Continuous Modes of Water Supply on Domestic Water Consumption, Water Resources Management, 23(12), (2009), 2555-2566, DOI 10.1007/s11269-008-9396-8

13 Yu G, Powell R S, Sterling M J H, Optimized pump scheduling in water distribution systems, Journal of Optimization Theory and Applications, 83(3), (1994), 463-488, DOI 10.1007/BF02207638

14 Scarpa F, Lobba A, Becciu G, Expeditious Pump Rescheduling in Multisource Water Distribution Networks, Procedia Engineering, 119, (2015), 1078-1087, DOI 10.1016/j.proeng.2015.08.938

15 Margeta J, Vodoopskrba naselja: planiranje, projektiranje, upravljanje, obrada vode, Faculty of Civil Engineering and Architecture, University of Split; Split, 2010.

16 Vojtesek J, Dostal P, Maslan M, Modelling And Simulation Of Water Tank, In: Squazzoni F, Baronio F, Archetti C, Castellani M (eds.), 28th European Conference on Modelling and Simulation (ECMS 2014); Brescia, Italy, 2014, pp. 247-253.

17 van Zyl J E, Piller O, le Gat Y, Sizing Municipal Storage Tanks Based on Reliability Criteria, Journal of Water Resources Planning and Management, 134(6), (2008), 548-555, DOI 10.1061/(ASCE)0733-9496(2008)134:6(548) 